
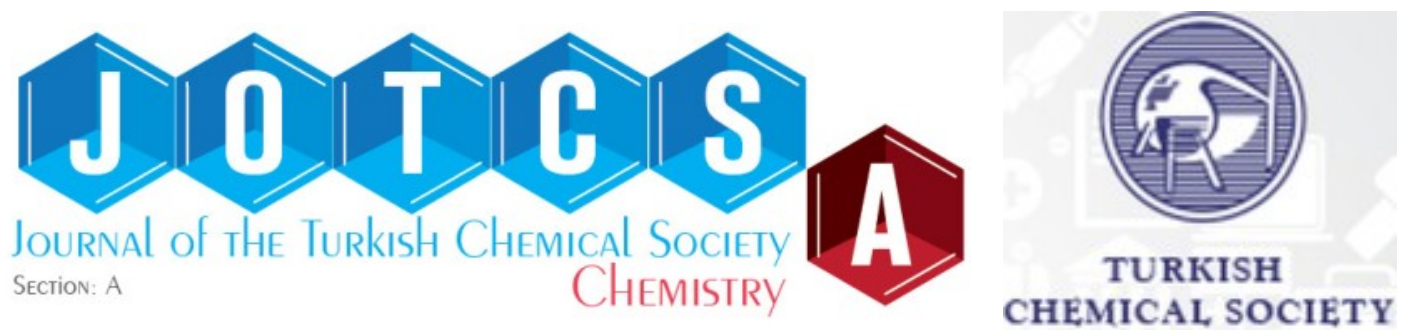

\title{
Functionalized Sepiolitic Clay Nanofibers as a Natural Ingredient in Medical Cosmetics
}

\author{
Birgül BENLi ${ }^{*}$ and Ecehan Aygül GöNÜL² $\triangle$ \\ ${ }^{1}$ Istanbul Technical University, Nanoscience and Nanoengineering Graduation School\& Mining Faculty, \\ Mineral Processing Engineering Department, 34469, Maslak, Turkey \\ ${ }^{2}$ Istanbul Bilgi University, School of Applied Sciences, Department of Fashion Design, 34440, Turkey
}

\begin{abstract}
Medical clay, also known as medicinal clay, was first used in Mesopotamia around $2500 \mathrm{BC}$ and is still a relevant topic today. Among typical medical clays, sepiolite, a fibrous clay in the family of palygorskite is often ignored by cosmetic brands as it is not found abundantly in nature as much as other clays like bentonite. However, much of the world reserves of this clay are in Turkey. In this study, antibacterial sepiolite clay was prepared from nanosilver added dispersed sepiolite samples. These Ag-nanoparticles (AgNPs) were formed according to green synthesis under microwave heating using the additives like alginate polymer and ascorbic acid later these fibers were put through serial dilution antibacterial tests using gram +/- bacteria (ATCC 25922 and ATCC 25923) for general quality control and determining minimum inhibitory concentrations. Although the best antibacterial clay samples (Ag-NPs have theoretically $30 \mathrm{mg} / \mathrm{L}$ of silver content) were washed at least five times with distilled water, it was observed that their antibacterial stability was still maintained. Finally, the morphology of sepiolite fibers smaller than $40 \mathrm{~nm}$ was characterized by AFM images show that highly dispersed single fibers can be used as a natural raw material and have a great opportunity in the development of new products in the cosmetic and medical sector.
\end{abstract}

Keywords: Antibacterial Clay, Sepiolite, Clay masks, Cosmetics, Medical Clay.

Submitted: December 25, 2020. Accepted: February 28, 2021.

Cite this: Benli B, Gönül EA. Functionalized Sepiolitic Clay Nanofibers as a Natural Ingredient in Medical Cosmetics. JOTCSA. 2021;8(2):471-6.

DOI: https://doi.org/10.18596/jotcsa.847163.

*Corresponding author. E-mail: benli@itu.edu.tr.

\section{INTRODUCTION}

Natural clay is a great alternative biodegradable fiber to be used in several innovative applications, its usage almost as old as mankind itself (1). Examples of different cultures in different periods using clays include; Native Americans who have used clays as a natural treatment to purify, protect the skin from the sun taking advantage of their excellent sun protection factor (SPF) properties, and heal the skin against bruises and wounds. Even animals, especially elephants, naturally use mud to keep insects away, protect themselves from excessive sun, to heal and protect their skin. Therefore, it can be said that clay and clay minerals have various usages as seen in Figure 1. 


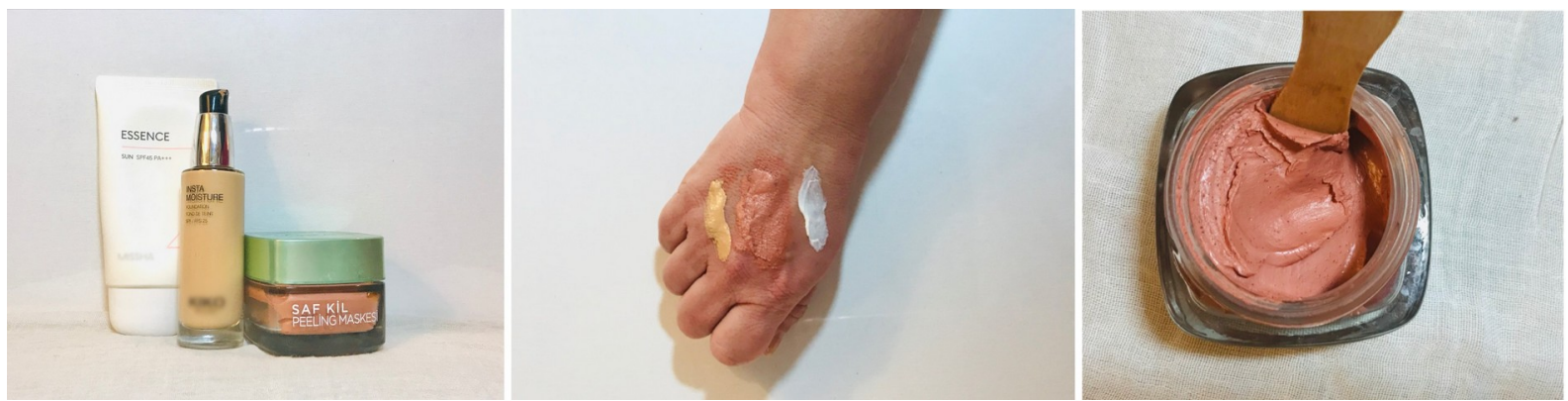

Figure 1. Clay masks and cream applications.

When mentioning medicinal clay often kaolin, bentonite, palygorskite (attapulgite) are considered, these group of clays has various uses as antibacterial agents, drug release matrixes, and high effective adsorbents in skin care and beauty products $(2,3)$. These fibrous clays are also desirable for being cheap as well as being sustainable for the environment. Sepiolite, a medical clay, has a unique natural mineral structure. Sepiolite is especially important since Turkey has the second-largest reservoir in the world as it is abundantly found in Eskişehir. Sepiolite is a hydrated magnesium silicate in a group of structural family of 2:1 phyllosilicates and a theoretical chemical formula of $\mathrm{Mg}_{8} \mathrm{Si}_{12} \mathrm{O}_{30}(\mathrm{OH})_{4}\left(\mathrm{OH}_{2}\right)_{4} \cdot 8 \mathrm{H}_{2} \mathrm{O}$. Its non-lamellar structural arrangement is similar to those of tubular halloysite $(2,3)$. This tubular structure creates open channels filled with both zeolitic and crystallized water $(4,5)$. Talc-like ribbons being linked to the next by inversion of $\mathrm{SiO}_{4}$ tetrahedra along a set of $\mathrm{Si}-\mathrm{O}-\mathrm{Si}$ bonds parallel to the fiber axis can be regarded as structural blocks alternating with structural cavities also called tunnels, associated with the internal surface of the silicates that grow up in the fiber direction. These tunnels and open channels occur in the unique structure of sepiolite fibers. The shape of sepiolite clay is either fibrous or can be seen as a fiber bundle under the atomic force microscopy (5), although the length of sepiolite fibers changes from different regions $(6,7)$. Figure 2 presents the inner tunnels and channels on the external surfaces of fibrous clays. The presence of zeolitic channels and the fibrous crystalline structure are the main reasons for fascinating fibrous structure, surface morphology, porosity, high surface area, and surface activity, production of stable dispersions at low concentrations $(8,9)$. These properties help produce unique catalytical, sorptive, and rheological characteristics for nanotechnological applications such as nanocomposites, anti-bacterial nanocoatings, and biosensors.
A

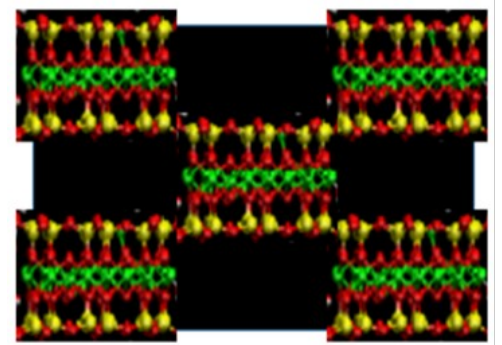

B

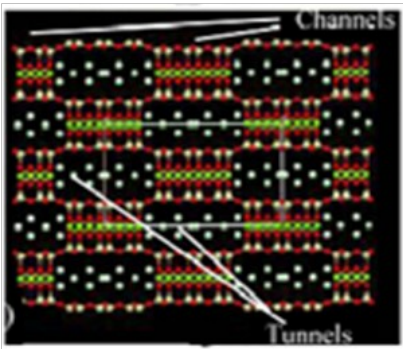

C

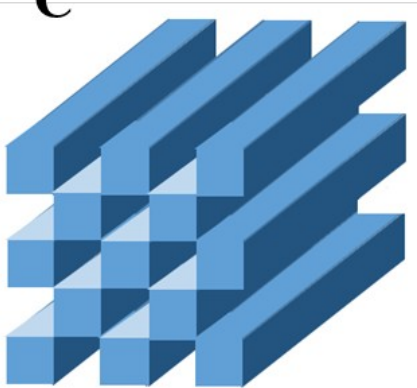

Figure 2. Schematics of fibrous sepiolite structure and textural characteristics: A) The sepiolite crystalline structure; red- oxygen atoms, yellow- silicon atoms, and green- magnesium atoms. B) the simulation result of molecular dynamics for the basal surface of sepiolite containing channels and tunnels; C) ideal the crosssection of sepiolite fiber.

On the other hand, silver has been used for its antibacterial properties from ancient times such as silver vessels that preserve water and keep liquid fresh as well as silver coins. As the grain size decreases to the nanometric scale, silver nanoparticles have different antibacterial properties such as strong toxicity to microorganisms, especially since silver has a larger surface area and higher surface reaction activities than the form of the metal structure (11). Therefore, this study aims to investigate the antibacterial potential of high-quality sepiolite nanofibers from the natural raw clay mineral via in-situ green synthesis of Ag-NPs. Therefore, this study aims to investigate the antibacterial potential of high-quality sepiolite nanofibers from natural raw clay mineral, through the in-situ green synthesis of Ag-NPs on fibers.

\section{MATERIALS AND METHODS}

The raw sepiolite samples were kindly obtained from the Tolsa Co., Turktaciri in Turkey. The main constituents were analyzed by ICP (inductively coupled plasma) spectrophotometry (ACME 
Analytical Lab., Canada), and quantitatively common metal oxides were determined as $49.85 \mathrm{wt}$. of $\mathrm{SiO}_{2}, 2.38$ wt. of $\mathrm{Al}_{2} \mathrm{O}_{3}, 0.87$ wt. of $\mathrm{Fe}_{2} \mathrm{O}_{3}, 2.65$ wt. of $\mathrm{CaO}$ and 20.15 wt. of $\mathrm{MgO}$. X-ray diffraction analyses were performed for mineralogical characterization of the sample (Shimadzu XRD6000, Shimadzu Corp., Tokyo, Japan). It was mineralogically found that the sample consists of $85 \pm 3 \%$ sepiolite, and together with dolomite along with minor minerals such as illite, palygorskite, calcite, smectite, dolomite, quartz, cristobalite, and feldspar. The sample was washed in water and dried at room temperature. Then, several multi-step processes were applied such as high-speed mixing, overnight-sedimentation, and drying steps that were applied several times to be able to prepare nano dispersed clay colloids from fibrous sepiolite clays.
The antibacterial properties of the sample were assessed by measuring its effectiveness against gram-negative (Escherichia coli, ATCC 25922) and gram-positive (Staphylococcus aureus). The microorganisms were obtained from the Culture Collections and Microorganisms Center in the Istanbul-Cerrahpaşa University (Turkey). A growth medium was prepared with a 50:50 mixture of LB broth (Luria-Bertani broth, Merck) and Agar-agar (Merck). Serial dilution tests for antibacterial susceptibility tests were performed according to the method shown in Figure 3 and the lowest antibacterial fiber concentration was determined by observing the fiber amount that inhibits the apparent growth of a microorganism known as the minimum inhibitory concentration (MIC).

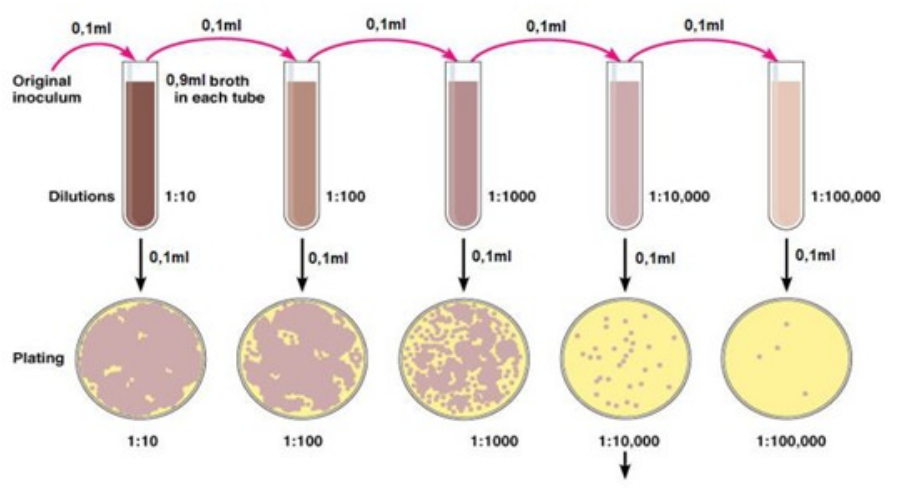

Figure 3. Main steps of the Serial Dilution method to determine minimum inhibitory concentration.

\begin{abstract}
Green synthesis of silver nanoparticles and Ag-Sep antibacterial material

$1 \%(\mathrm{w} / \mathrm{v})$ sodium alginate solution was prepared in long-term mixing at room temperature. $1 \%(\mathrm{w} / \mathrm{v})$ ascorbic acid solution and $50 \mathrm{mM} \mathrm{AgNO}_{3}$ solution were dissolved in $25 \mathrm{~mL}$. The solutions later were mixed and heated using a microwave for a total of 15 minutes. Lastly, $1 \% \mathrm{NaOH}$ and $1 \mathrm{~N} \mathrm{HCl}$ were used to adjust the $\mathrm{pH}$ of the solutions when needed. Afterward, the prepared solutions were centrifuged at $15000 \mathrm{rpm}$ for 15 minutes. And then silver nanoparticles containing the suspension was added into $3 \%$ of dispersed sepiolite solution and treated in a microwave oven at $200{ }^{\circ} \mathrm{C}$ for $5 \mathrm{~min}$. This sample was called as Ag-Sep.
\end{abstract}

\section{Atomic Force Microscopy (AFM) Studies}

AFM images of the particles were conducted using Park Systems, XE-70E in contact mode with $0.5 \mathrm{~Hz}$ scanning speed. During contact mode measurements, NSC36/Cr-Au type of cantilevers was selected. Before measurements, all samples were specifically prepared similarly to our previous study (12). Briefly, one drop of $1 \%$ of sepiolite dispersion contains Ag-NPs (theoretically $50 \mathrm{mg} / \mathrm{L}$ silver content) were dropped on the cleavage of fresh mica substrate. In the moisture-controlled medium ambient conditions $\left(22 \pm 2{ }^{\circ} \mathrm{C}\right)$ AFM measurements were taken. Using UV Cleaner (Bioforce Nanosciences) each cantilever was exposed to $\mathrm{UV} / \mathrm{O}_{3}$ for $15 \mathrm{~min}$ and high purity nitrogen gases before each experiment to decontamination for any possible organic reactive on each cantilever. All AFM images were processed by Park Systems, XEI Image Processor.

\section{RESULTS AND DISCUSSION}

Silver nanoparticles were successfully enabled with sepiolite fibers to gain antibacterial properties. Bacterial strength notably increased up to $20 \mathrm{mg} / \mathrm{L}$ in silver content for both gram-negative E.coli and gram-positive S.aureus. And then, their efficiency to gram +/- bacteria was seen after the content reached $25 \mathrm{mg} / \mathrm{L} \mathrm{Ag}^{+}$to the theoretical silver concentration. The results are shown in Figure 3. On the other hand, it was clear that the pure raw sepiolite fibers have not any inhibitory effect on the antibacterial properties against neither S. Aureus nor E. coli. 


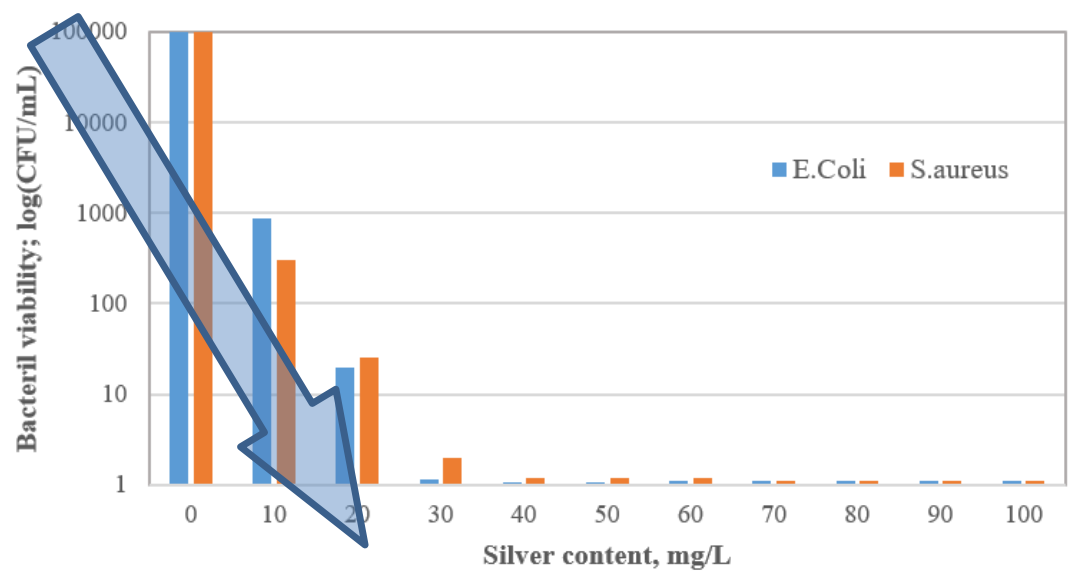

Figure 3. Bacterial viability of gram +/- bacteria against silver nanoparticle added sepiolite fibers.

Figure 4 shows the sepiolite was homogeneously dispersed in Ag-NPs contained aqueous solution. We can say that even after two months, it is still suspended in the water. However, it is seen that the dispersion of the other untreated sepiolite has already settled.

The success of the procedure was examined with AFM images. Also, the size and shape of the fibrous type of sepiolite were determined by Atomic Force Microscopy (AFM) in Contact Mode. This image proves the size and shape of the fibers as a morphological approach using at least 30-line profile analysis. The fibers were dispersed together into two categories: mostly separated fibers and little bundles. These dispersed ones are the size of $200 \pm 11 \mathrm{~nm}$ in diameter and $1 \pm 0.4 \mu$ of length. In this image, excess clay particles and silver nanoparticles were also seen on the cleavage mica substrate. On the other hand, small bundles below $200 \mathrm{~nm}$ diameters in sizes were measured such as $143 \pm 6 \mathrm{~nm}$ in diameter (Figure 5).

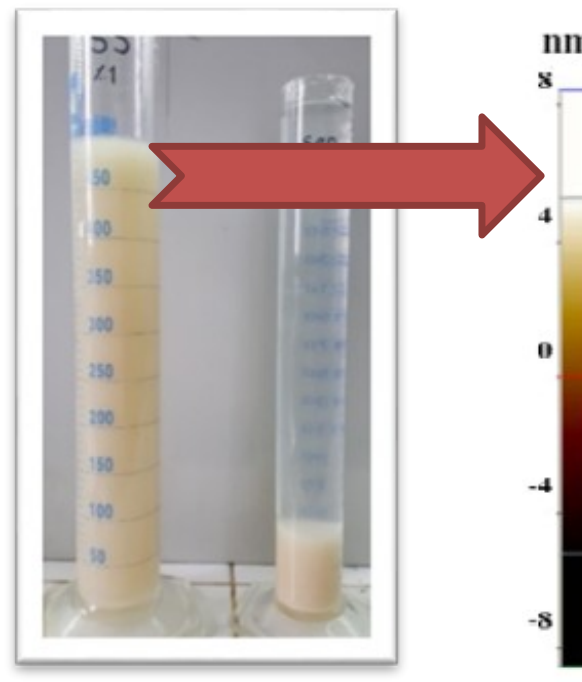

$\mathrm{nm}$
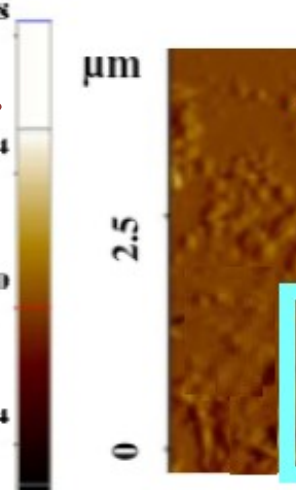

\section{Ag-NPs loaded} Fibrous

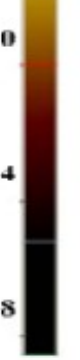

0

5

$\mu \mathrm{m} \quad 7.5$

Figure 4. Sepiolite dispersion and AFM image of silver nanoparticles loaded sepiolite fibers on fresh mica cleavage. 

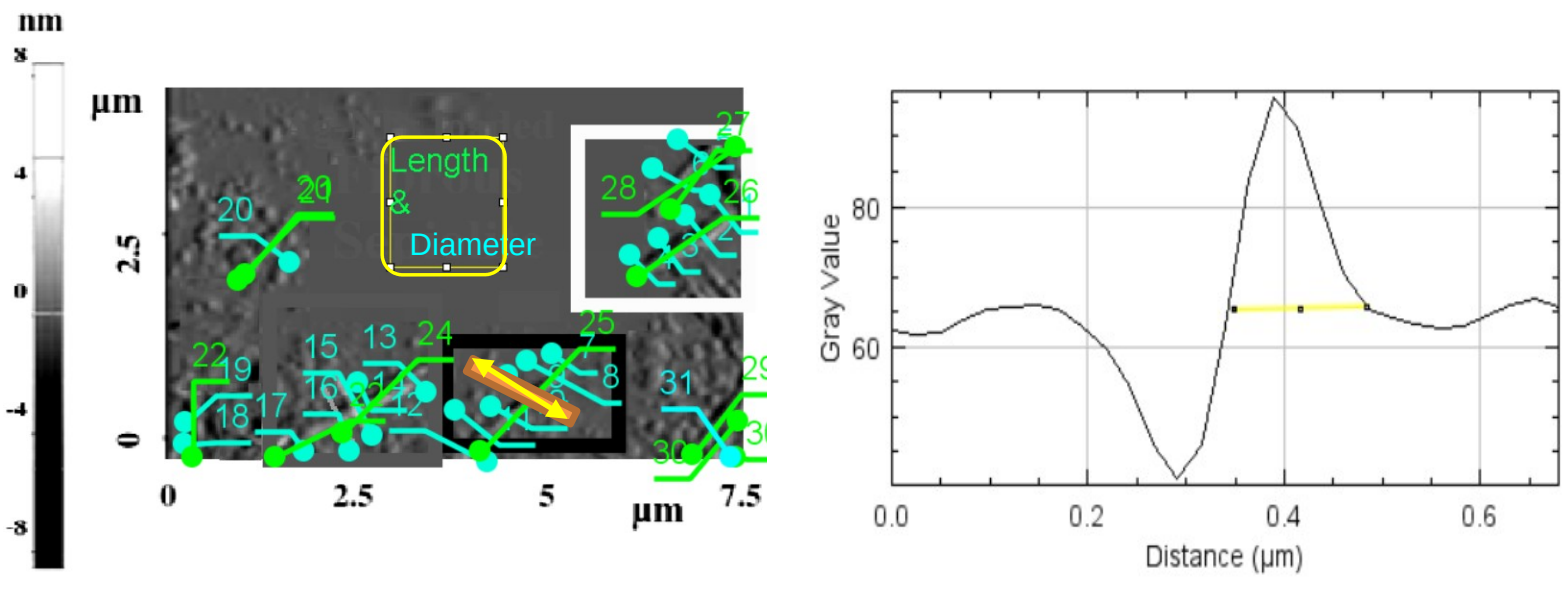

Figure 5. AFM topographic image (left) as sepiolite fibers, line profile (right) indicating a fiber diameter of $143 \mathrm{~nm}$.

Mechanism of interaction between bacteria and sepiolite

Bacterial cell walls are negatively charged under physiologic conditions. This is due to the functional groups on the surface of the bacteria. These functional groups like carboxylates in lipoproteins cause a net negative charge. In the case of the outer membrane of $E$. coli, a gram-negative bacterium covering a thin layer of peptidoglycan, that provides a hydrophilic surface. Similarly, Gram + bacteria have a peptidoglycan layer that is much thicker and attracts more positive ions. Gram + bacteria are more vulnerable to the attack of antibacterial silver agents and damage more like Figure 6.

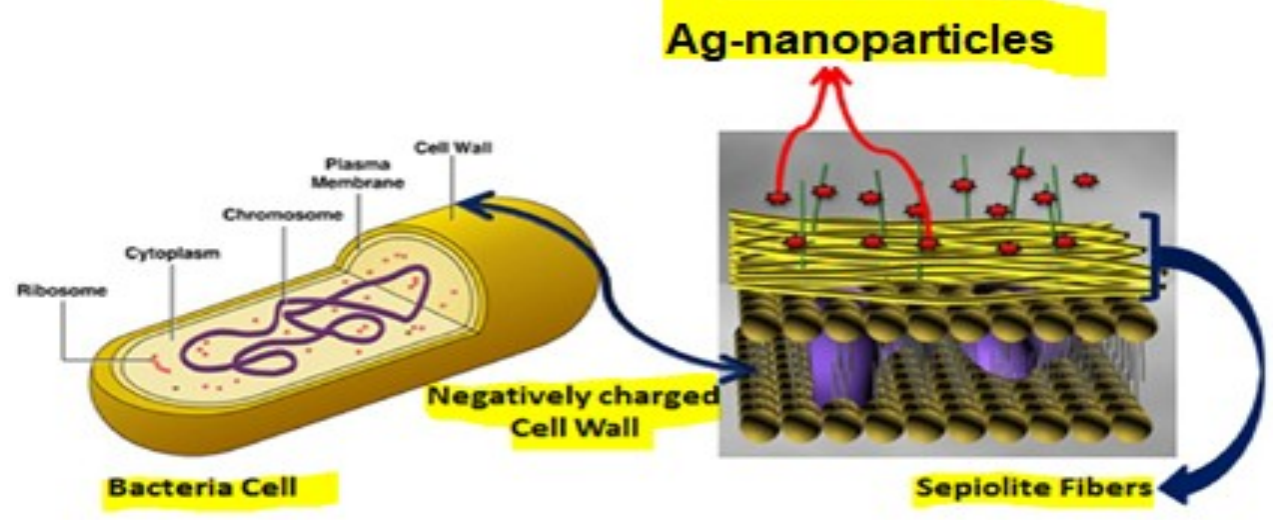

Figure 6. The mechanism of the interaction between bacteria and antibacterial clay-based structure.

One of the mechanisms is the silver adsorption from AgNPs added sepiolite fibers on the cell membrane. Here, the main ionic interaction is the mobility of silver ions $\left(\mathrm{Ag}^{+}\right)$from the solution to the cell membrane. The released silver ions might have damaged the cell membrane after the biosorption of silver causes mostly by protein coagulation. Also, other biological processes are possible like cell wall pits, respiratory chain inactivation, reduction of membrane permeability, and biosorption process. On the other hand, penetration to the bacteria could be taken into account for small-sized AgNPs. Therefore, the induced permeability of the cell membrane is mainly dominant.

\section{CONCLUSION}

Antibacterial sepiolite fibers separated from their impurities and loaded with silver nanoparticles show excellent antibacterial activity. In this study, highquality sepiolite nanofibers are deliberated from natural raw Turkish clay by easy and effective mixing and sedimentation process. After green synthesis of silver nanoparticles, $30 \mathrm{mg} / \mathrm{L}$ theoretical silver content was enough to obtain antibacterial fibers. The anisotropic surface structure of sepiolite fibers was also investigated by the morphological analysis from AFM images. In conclusion, sepiolite an often overlooked clay has proven to be an adequate ingredient for cosmetics namely skincare to be used as an active ingredient for its 
antibacterial and good adsorbent properties which could pair up well in medical cosmetics as effective drug carriers.

\section{ACKNOWLEDGEMENTS}

The authors would like to thank the Engineering Research Group of the Scientific and Technological Research Council of Turkey (TUBITAK) for supporting our project: MAG-217M275 entitled Improvement of Surface Properties of Body-soluble Magnesium Implants by Coating with Biodegradable Alginate Based Sepiolite Composite Thin Films. This paper was presented at the 4th International Cosmetic Congress as an oral presentation.

\section{REFERENCES}

1 Benli, B. Nanotechnology with clay-based nanostructures since ancient ages. Kibited, 2008; 1(3): 143-62.

2 Galan, EP. The identification and nomenclature of sepiolite and palygorskite (a historical perspective). In book: Natural Mineral Nanotubes: Properties and Applications, Pooria Pasbakhsh, G. Jock Churchman (Editors), Apple Academic Press. 2015, Chapter 3: 69-84.

3 Galindo-Lopez, A, Viseras, C. Pharmaceutical and Cosmetic Applications of Clays. Interface Science and Technology, 2004; 1: 267-89.

4 Cavallaro, G, Fakhrullin, R, Pasbakhh, P. Clay nanoparticles: Properties and Applications. 2020, 1st Edition, Elsevier.

5 Benli, B, Du, H, Celik, MS. The anisotropic characteristics of natural fibrous sepiolite as revealed by contact angle, surface free energy, AFM, and molecular dynamics simulation. Colloid. Surface. 2012; A 408: 22-31.

6 García-Romero, E. \& Suárez, M. Sepiolitepalygorskite: Textural study and genetic considerations. Appl. Clay Sci. 2013; 86: 129-44.

7 Tian, L., Wang, L., Wang, K. et al. The preparation and properties of porous sepiolite Ceramics. Sci. Rep. 2019; 9: 7337.

8 Benli, B, Yalın, C. The influence of silver and copper ions on the antibacterial activity and local electrical properties of single sepiolite fiber: A conductive atomic force microscopy (C-AFM) study. Applied Clay Science. 2017; 146: 449-56.

9 Ruiz-Hitzky, E. Molecular access to intracrystalline tunnels of sepiolite. J. Mater. Chem., 2001; 11: 86-91.

10 Aranda, P, Darder, M, Wicklein, B, Rytwo, G, RuizHitzky, E. Clay-Organic Interfaces for Design of Functional Hybrid Materials. (Eds. Delvile, M, Taubert, A) Hybrid Organic-Inorganic Interfaces: Towards Advanced Functional Materials. Wiley-VCH Verlag GmbH \& Co., 2017.

11 Ipe, DS, Kumar PT, Sudheesh, LRM, Hamlet, SM. Silver Nanoparticles at Biocompatible Dosage Synergistically Increases Bacterial Susceptibility to Antibiotics. Frontiers in Microbiology. 2020; 11, 1074: 1-11.

12 Benli, B. Effects of humic acid release from sepiolite on the interfacial and rheological properties of alkaline dispersions. Applied Clay Science. 2014; 102: 1-7. 